\title{
The Sea Level Budget Since 2003: Inference on the Deep Ocean Heat Content
}

\author{
Habib B. Dieng $\cdot$ Hindumathi Palanisamy $\cdot$ Anny Cazenave $\cdot$ \\ Benoit Meyssignac $\cdot$ Karina von Schuckmann
}

Received: 26 September 2014/ Accepted: 2 January 2015/Published online: 28 January 2015

(C) The Author(s) 2015. This article is published with open access at Springerlink.com

\begin{abstract}
This study provides an overview of the various components of the global mean sea level evolution over two time spans: (1) 2005-2012 (corresponding to the full deployment of the Argo program) and (2) 2003-2012. Using a sea level budget approach, we compare altimetry-based global mean sea level, global ocean mass from GRACE space gravimetry and steric sea level from Argo and other in situ measurements. One goal of this study is to investigate whether it is possible to constrain the deep ocean contribution to the global mean sea level rise over the last decade. This question is particularly relevant, considering the current debate about the 'hiatus,' i.e., the observed recent pause of the global mean air and sea surface temperature evolution while the planet is still in thermal imbalance. We consider a total of 16 different data sets. Differences are noticed between data sets related to each variable (sea level, ocean mass and steric sea level), mostly due to data processing issues. Therefore, we perform the analysis using averages of the available data sets. For each period, we find that, when removing from the global mean sea level, the contributions of the global mean ocean mass and steric sea level (estimated for the $0-1,500 \mathrm{~m}$ ocean layer), there remains a residual signal displaying a positive slope of $0.3 \pm 0.6$ and $0.55 \pm 0.6 \mathrm{~mm} /$ year over 2005-2012 and 2003-2012, respectively. Comparing with an ocean reanalysis and according to direct (but sparse) ocean temperature measurements below $1,500 \mathrm{~m}$, it seems unlikely that the observed residual signal can be attributed to deep (below 1,500 m) ocean warming, in agreement with other recently published results. We estimate that it possibly reflects, at least partly, the signature of a missing upper ocean steric signal in regions uncovered by current observing systems. Our study also shows a steady warming increase since 2003 of the $700-1,500 \mathrm{~m}$ ocean layer (amounting $\sim 0.2 \mathrm{~mm} /$ year in steric sea level equivalent), confirming previous findings, but seen in our study in each of the eight different steric data sets considered.
\end{abstract}

H. B. Dieng $\cdot$ H. Palanisamy $\cdot$ A. Cazenave $(\bowtie) \cdot$ B. Meyssignac LEGOS-CNES, 18 Avenue E. Belin, 31401 Toulouse Cedex 9, France e-mail: anny.cazenave@legos.obs-mip.fr

K. von Schuckmann

Mediterranean Institute for Oceanography, University of Toulon, Toulon, France 
Keywords Sea level rise $\cdot$ Thermal expansion - Ocean mass - Deep ocean warming

\section{Introduction}

Sea level is an interesting quantity in Earth sciences research as it integrates variations from different climatic and non-climatic variables. For example, in terms of global mean, current sea level rise mostly results from thermal expansion of seawater due to ocean temperature changes and water mass addition into ocean basins due to glacier melting, ice sheet mass loss and land water storage changes of anthropogenic origin (e.g., Leuliette and Willis 2011; Chen et al. 2013; Church et al. 2013). At interannual timescales, in particular during ENSO (El Nino-Southern Oscillation) events, global mean sea level fluctuations are largely due to land-ocean asymmetry in precipitation, causing temporary ocean mass excess (during El Nino) or deficit (during La Nina) (Boening et al. 2012; Cazenave et al. 2012, 2014; Fasullo et al. 2013). While regional variations in absolute sea level mostly result from ocean temperature and salinity variations (and to a lesser extent from direct atmospheric forcing on the sea surface) (Stammer et al. 2013), non-climatic factors also play a role. In effect, the viscous/elastic response of the solid Earth to past (i.e., last deglaciation) and ongoing land ice melt causes complex deformations of ocean basins and changes in the mutual attraction of ice-water bodies, and hence of sea level (e.g., Stammer et al. 2013). Finally, along coastlines, relative sea level changes occur because of a combination of absolute sea level changes and vertical movements of the Earth's crust (Woppelmann et al. 2009).

In the 5th Assessment Report (AR5) of the Intergovernmental Panel on Climate Change (IPCC), it was reported that over the 1993-2010 time span (corresponding to the high-precision satellite altimetry era), the rate of global mean sea level (GMSL) rise is due to the combined effects of land ice melt (50\%), ocean thermal expansion (37\%) and anthropogenic land water storage decrease (13\%) (Church et al. 2013). The sum of these contributions amounts to $2.8 \pm 0.5 \mathrm{~mm} /$ year, a value only slightly lower than the rate of sea level rise observed by altimeter satellites, of $3.2 \pm 0.4 \mathrm{~mm} /$ year. Although of the same order of magnitude as associated uncertainties, the difference may also reflect other contributions either not or incompletely accounted for, e.g., the deep ocean (below 700-1,000 $\mathrm{m}$ depth where the coverage of available data is poor or non-existent).

In the IPCC 4th Assessment Report (AR4), the sea level budget was estimated over the 1993-2003 time span (Bindoff et al. 2007). Over that decade, the thermal expansion contribution was $\sim 50 \%$ the rate of sea level rise, i.e., significantly larger than the 1993-2010 average (note, however, that in AR4, thermal expansion estimates were contaminated by Expandable Bathy Thermographers-XBT biases). In fact, the sea level components are not constant through time. During the last 10-15 years, the land ice (mostly the ice sheets) component has accelerated (i.e., Shepherd et al. 2012; see also IPCC AR5 and references herein) while the upper ocean thermal expansion has increased less rapidly than during the 1993-2003 decade (Lyman et al. 2010). This recent slower rate in thermal expansion of the upper ocean coincides with the pause (also called the 'hiatus,' e.g., Held 2013) in global mean air and sea surface temperature evolution observed since the early 2000s (e.g., Trenberth and Fasullo 2013; Smith 2013). The current global warming hiatus is puzzling because greenhouse gases have 
continued to accumulate at an increased rate (Peters et al. 2012) and the Earth's energy imbalance at the top of the atmosphere is estimated to still be positive, on the order of 0.5-1 Wm ${ }^{-2}$ (e.g., Hansen et al. 2011; Trenberth et al. 2014). This issue has been the object of considerable attention in the very recent years, and different explanations have been proposed, ranging from reduced radiative forcing due to prolonged solar minimum, increased aerosols and numerous volcanic eruptions, changes in stratospheric water vapor, enhanced heat uptake in the deep ocean, either in the Pacific or Atlantic regions (e.g., Trenberth and Fasullo 2010, 2013; Hansen et al. 2011; Solomon et al. 2010; Guemas et al. 2013; Kosaka and Xie 2013 Balmaseda et al. 2013a; Watanabe et al. 2013; England et al. 2014; Chen and Tung 2014). While deep ocean heat uptake is currently the favored explanation of the hiatus, no consensus yet exists on the exact mechanism at work and on the place where deep ocean warming may occur (e.g., Goddard 2014; Trenberth et al. 2014; Chen and Tung 2014).

Accurate observations of sea level rise and its components (ocean thermal expansion and ocean mass change) can, in principle, help to constrain the problem (e.g., von Schuckmann et al. 2014). In particular satellite altimetry-based GMSL rise corrected for ocean mass change (e.g., using GRACE space gravimetry data over the oceans) provides an estimate of the total (full depth integrated) ocean thermal expansion (or equivalently ocean heat content). Comparison with observed Argo-based ocean thermal expansion (down to $\sim 1,500 \mathrm{~m}$ depth) may help to quantify any deep ocean contribution (below $1,500 \mathrm{~m}$ ) and geographically localize any ocean warming. The first issue is addressed in the present study. Our analysis focusses on the 2003-2012 decade which corresponds to the hiatus period and the availability of new observing systems for estimating thermal expansion and ocean mass (nearly full ocean temperature and salinity coverage down to 2,000 $\mathrm{m}$ from Argo floats and direct ocean mass measurements from GRACE space gravimetry). Time series of satellite altimetry-based sea level, thermal expansion and ocean mass components are currently constructed by different groups (see Sect. 2) so that several data sets of each variable are available. But as we will see below, for some of them, in particular ocean thermal expansion, significant discrepancies are noticed between the data sets. Thus, part of our study consists of discussing the differences observed between the different records and estimate the uncertainty of each component. We further address the question: Can we close the sea level budget with available data sets for sea level and components or, if not, can we extract a significant residual possibly related to the deep ocean contribution? The present study deals with global mean time series. Contributions from oceanic regions will be presented in another study. Inside the 2003-2012 time span, two subperiods are considered: period P1 covering January 2005 to December 2012, corresponding to quasi global coverage of Argo data (before 2005, the Argo coverage is incomplete, e.g., von Schuckmann and Le Traon 2011), and period P2 covering January 2003 to December 2012 where GRACE data are available, as well as several steric data sets and ocean reanalyses products (in general available over a longer time span, e.g., 1950-present). In the following, we study periods P1 (2005-2012) and P2 (2003-2012).

While our manuscript was under review, another study by Llovel et al. (2014) was published on the same issue. Llovel et al. (2014) consider the 2005-2013 time span, and not as many data sets as in the present study, but their conclusion is not at odds with ours. In the last section, we discuss their results and compare them with ours. 


\section{Data}

\subsection{Sea Level Data}

We used five different products from five processing groups for the altimetry-based sea level data:

1. Archiving Validation and Interpretation Satellite Oceanographic Center (AVISO; http:// www.aviso.altimetry.fr/en/data/products/ocean-indicators-products/actualitesindicateursdes-oceansniveau-moyen-des-mersindexhtml.html)

2. Colorado University (CU Release 3; http://sealevel.colorado.edu/)

3. Goddard Space Flight Center (GSFC version 2; http://podaac-ftp.jpl.nasa.gov/dataset/ MERGED_TP_J1_OSTM_OST_GMSL_ASCII_V2)

4. National Oceanographic and Atmospheric Administration (NOAA; http://www.star. nesdis.noaa.gov/sod/lsa/SeaLevelRise/LSA_SLR_timeseries_global.php)

5. Commonwealth Scientific and Industrial Research Organization (CSIRO; www.cmar. csiro.au/sealevel/sl_data_cmar.html).

All five sea level data sets are based on Topex/Poseidon, Jason-1 and Jason-2 data averaged over the $66^{\circ} \mathrm{S}-66^{\circ} \mathrm{N}$ domain, except for the CSIRO data averaged between $65^{\circ} \mathrm{S}$ and $65^{\circ} \mathrm{N}$. For each product, a set of instrumental and geophysical corrections is applied (details are given on the websites of each data set). In addition, the effect of glacial isostatic adjustment (GIA, i.e., a small correction of $-0.3 \mathrm{~mm} / \mathrm{year}$, Peltier 2004) is accounted for in each sea level time series except in the NOAA data set. We thus corrected the latter sea level data for the GIA effect, using the $-0.3 \mathrm{~mm} /$ year value. The five sea level time series (AVISO, CU, GSFC, NOAA and CSIRO) are obtained either by directly averaging the along-track sea surface height data (e.g., CU) or by firstly gridding the unevenly distributed along-track data and then performing grid averaging (e.g., AVISO and NOAA). In all cases, an area weighting is applied. In addition to the geographical averaging method, other differences exist between the GMSL data sets because of the applied geophysical and instrumental corrections and the number of satellites considered (discussion on these differences can be found in Masters et al. 2012 and Henry et al. 2014). The sea level time series used in this study cover the period January 2003-December 2012.

Recently, in the context of the European Space Agency (ESA) Climate Change Initiative (CCI) 'Sea Level' project (ftp.esa-sealevel-cci.org/Products/SeaLevel-ECV/ V1_11092012/), a new, improved product, combining the Topex/Poseidon and Jason-1/2 with the ERS-1/2 and Envisat missions, has been computed (Ablain et al. 2014). However, at the date of writing it is available until December 2010 only. Even if, for the sea level budget, we will not use the CCI data set as it does not yet extend to 2012, we will compare the CCI-based GMSL with the other data sets during their overlapping time span (January 2003-December 2010) (see Sect. 3.1).

\subsection{Ocean Mass Data}

For estimating the ocean mass component, we used three different data sets: The GRACE Release 05 products from the Center for Space Research from Texas University (CSR RL05), the German GeoForschungsZentrum (GFZ RL05) and the Jet Propulsion Laboratory (JPL RL05). To study the ocean mass evolution, a specific processing has been carried out by D. Chambers, using the GRACE Release 05 data sets over the oceans. In effect, as warned on the http://grace.jp.nasa.gov Web site, gridded Release 05 data cannot be used to 
compute ocean mass changes because they have the global mean removed. In this study, we used the Chambers' ocean data. They are provided as global mean (averaged over the $90^{\circ} \mathrm{S}-90^{\circ} \mathrm{N}$ domain) time series with associated uncertainty. They are publicly available from https://dl.dropboxusercontent.com/u/31563267/ocean_mass_orig.txt. The processing methodology is described in Johnson and Chambers (2013) (see also Chambers and Schroeter 2011; Chambers and Bonin 2012). The GIA component has been subtracted from each GRACE ocean mass time series using the GIA correction computed in Chambers et al. (2010).

\subsection{Steric Data}

The steric component is estimated using in situ ocean temperature and salinity data sets. We considered seven different datasets, including four Argo products, plus an ocean reanalysis.

\subsubsection{Period P1: Argo Data}

We used Argo temperature and salinity data sets provided by four different groups:

- the International Pacific Research Center (IPRC),

- the Japan Agency for Marine-Earth Science and Technology (Jamstec),

- the Scripps Institution of Oceanography (SCRIPPS).

These data sets are available at monthly intervals on a global $1^{\circ} \times 1^{\circ}$ grid down to $2,000 \mathrm{~m}$, over the period January 2005-December 2012. They can be downloaded from the http://www.argo.ucsd.edu/Gridded_fields Web site.

Using these data sets, we computed the steric sea level time series (and associated uncertainty; but note that only Jamstec provides errors), integrating the data over the $0-1,500 \mathrm{~m}$ depth range. The gridded steric time series from IPRC, Jamstec and SCRIPPS are estimated over the $62.5^{\circ} \mathrm{S}-64.5^{\circ} \mathrm{N}, 60.5^{\circ} \mathrm{S}-70.5^{\circ} \mathrm{N}$ and $61.5^{\circ} \mathrm{S}-64.5^{\circ} \mathrm{N}$ domains, respectively (i.e., corresponding to the data availability). An area weighting is applied when computing the global mean time series.

We also used an updated version of the global mean steric time series computed by von Schuckmann and Le Traon (2011) (0-1,500 m ocean layer). This monthly time series is based on a weighted box averaging scheme of Argo data, within the $60^{\circ} \mathrm{S}-60^{\circ} \mathrm{N}$ domain. In the following, this data set is called $\mathrm{KvS}$.

Therefore, a total of four steric data sets are considered over period P1.

\subsubsection{Period P2}

In addition to the Jamstec data set, we also used other steric data sets to study the sea level budget over period P2 (since 2003): an updated version of Ishii and Kimoto (2009), the NOAA data set from Levitus et al. (2012) and the EN4 data set (Good et al. 2013). In addition, we also used the ORAS4 reanalysis from Balmaseda et al. (2013b). Over the recent years, these data sets integrate Argo data. Prior to Argo, most data are based on XBT devices and other in situ measurements (see Abraham et al. 2013). A few details on these data sets are given below:

- Ishii and Kimoto (2009) data set (called IK hereinafter): We used the updated 6.13 version available at http://rda.ucar.edu/datasets/ds285.3/. It is based on the World 
Ocean Database 2005 and World Ocean Atlas 2005 (WOD05 and WOA05), the Global Temperature-Salinity dataset in the tropical Pacific from the Institut de Recherche pour le Development (IRD, France) and the Centennial in situ Observation Based Estimates (COBE) sea surface temperature. The XBT depth bias correction is applied in the current version. The temperature and salinity data are available at monthly intervals over 24 depth levels ranging from the ocean surface down to $1,500 \mathrm{~m}$ depth, on a global $1^{\circ} \times 1^{\circ}$ grid from January 1945 to December 2012 (see Ishii and Kimoto 2009 for details).

- NOAA data set: Available at https://www.nodc.noaa.gov/OC5/3M_HEAT_ CONTENT. As described in Levitus et al. (2012), this $1^{\circ} \times 1^{\circ}$ data set uses the World Ocean Database 2009 (WOD09) plus additional data processed since 2009. Bias corrections are applied to the MBT (Mechanical BathyThermographs) and XBT data as described by Levitus et al. (2009). The temperature and salinity grids below $700 \mathrm{~m}$ are not available prior to January 2005. Thus, for the P2 time span, we computed the NOAA steric time series considering data down to $700 \mathrm{~m}$ only. Data are given at 3-month interval. Therefore, we interpolated the NOAA time series at monthly intervals to be consistent with the other steric time series.

- EN4 data set: We used the EN4.0.2 version from the Met Office Hadley Centre (http:// www.metoffice.gov.uk/hadobs/en4/download-en4-0-2.html). This data set is based on the quality controlled subsurface ocean temperature and salinity profiles and objective analyses. The EN4.0.2 data set is an incremental development of the previous EN2 and EN3 versions. Data sources include the WOD09, Global Temperature and Salinity Profile Program (GTSPP) and Argo data from Argo Global Data Assembly Centres (GDACs). The EN4.0.2 temperature and salinity data are corrected for the XBT and MBT bias. The temperature and salinity data are available at monthly intervals over 40 depth levels ranging from the ocean surface down to $5,350 \mathrm{~m}$ depth, on a global $1^{\circ} \times 1^{\circ}$ grid from January 1900 to December 2013. Details on the data processing are given in Good et al. (2013).

- The ORAS4 reanalysis from Balmaseda et al. (2013b) (https://icdc.zmaw.de/easy_init_ ocean.html?\&L=1\#c2231). It is based on the Nucleus for European Modelling of the Ocean (NEMO) ocean circulation model (version 3.0) with data assimilation. Assimilated data include temperature and salinity profiles from EN3 version 2a (1958-2009), along-track altimetry-based sea level anomalies and global sea level trend from AVISO, sea surface temperature and sea ice from the ERA-40 archive (prior to November 1981), from NCEP (National Centers for Environmental Prediction) OI version 2 (1981 until December 2009) and from OSTIA (Operational Sea Surface Temperature and Sea Ice Analysis; January 2010 onwards). The ORAS4 temperature and salinity data are available at monthly intervals over 42 depth levels ranging from the ocean surface down to 5,350 m depth, on a global $1^{\circ} \times 1^{\circ}$ grid from January 1958 to December 2009. Details on the data processing are given in Balmaseda et al. (2013b).

Except for NOAA for which steric sea level grids are directly available, we computed the steric sea level time series and associated errors for the P2 period, integrating the data over the $0-1,500 \mathrm{~m}$ depth range. The global mean steric time series were further estimated by geographically averaging the gridded data (area weighting applied).

For the whole set of time series, annual and semiannual cycles were removed and residual time series were smoothed using a 3-month moving window. 


\section{Data Analysis}

\subsection{Global Mean Sea Level and Ocean Mass Time Series}

Figure 1a shows plots of the GMSL time series without the CCI data over 2003-2012. We note that the CU and GSFC sea level curves are very close, as are the NOAA and AVISO curves. The CSIRO curve agrees better with NOAA and AVISO than with the other two, at least for the second part of the study time span. Some differences are observed between the time series on short time spans $(<2-3$ years). In terms of trends, differences up to $\sim 0.35 \mathrm{~mm} /$ year are noticed between the AVISO, CSIRO, NOAA groups on the one hand, and $\mathrm{CU}$ and GSFC on the other hand, the latter groups giving slower rates. As shown in Masters et al. (2012) and Henry et al. (2014), most of these differences (for both interannual fluctuations and trends) result from the mapping process adopted by the different groups. Table 1 gives the GMSL trend estimates for the five time series and their means, over P1 and P2 periods.

Figure 1b plots the same five GMSL time series as in Fig. 1a, together with the CCI GMSL over January 2003-December 2010 time span. Slight differences are observed between the CCI and other GMSL time series at interannual timescales. Table 1 also gives the GMSL trends over January 2003-December 2010. We note that the CCI trend $(2.75 \mathrm{~mm} /$ year $)$ is equal to the mean trend of the other five time series $(2.71 \mathrm{~mm} / \mathrm{year})$ over this time span. In the following, we will only consider the mean GMSL time series based on averaging the AVISO, CU, NOAA, GSFC and CSIRO time series.

Figure 1c shows the three ocean mass time series over 2003-2012. The global ocean mass (GOM) curves agree well, both in terms of trend and interannual variability. The year-to-year discrepancies between the three curves remain within the error bars of each time series. GOM trends for each data set and means, over P1 and P2 periods are given in Table 1.

Note that the reasonably good agreement among the GMSL and GOM products does not imply anything on their absolute accuracy. However, for the GMSL, external calibration with tide gauge data and assessment of all sources of errors acting on the satellite altimetry system allows us to estimate the GMSL trend and the year-to-year mean sea level anomalies accurate to $\sim 0.4 \mathrm{~mm} /$ year and 1-2 mm (Ablain et al. 2009, 2014). For the ocean mass component, it is not possible to do external calibration. Although the GRACE-based ocean mass could be compared to the sum of individual mass components (glacier melting, ice sheet mass loss, land water storage change, atmospheric water vapor change), the latter are still too uncertain to perform any reliable calibration at a global scale. The GRACE-based ocean mass precision has been estimated to $1.5 \mathrm{~mm}$ for individual monthly gridded values (Wahr et al. 2006; Chambers and Bonin 2012). In terms of trend, the main uncertainty comes from the GIA correction (estimated at the $0.3 \mathrm{~mm} /$ year level, Chambers et al. 2010).

Figure 2 plots mean GMSL (average of the five products), mean GOM (average of the three products) and difference 'GMSL minus GOM' (based on the above averaged curves) with associated uncertainty. For the mean GMSL, the uncertainty is based on the dispersion of each time series with respect to the mean. For the mean GOM, it is based on the quadratic sum of individual errors. Estimating the uncertainty of the mean GOM curve from the dispersion of individual curves gives exactly the same result.

Over P2 (2003-2012), the linear trends amount to $2.82 \pm 0.10 \mathrm{~mm} / \mathrm{year}$ for the mean GMSL, $1.70 \pm 0.10 \mathrm{~mm} /$ year for the mean GOM and $1.12 \pm 0.13 \mathrm{~mm} /$ year for the difference. Uncertainties quoted here are formal errors (1 standard deviation, SD). More realistic errors are discussed below (Sect. 4). The GMSL minus GOM time series 
Fig. 1 a Global mean sea level (GMSL) time series (January 2003-December 2012) from the five satellite altimetry processing groups (AVISO, CU, CSIRO, GSFC and NOAA). b Global mean sea level (GMSL) time series (January 2003-December 2010) from the five satellite altimetry processing groups (AVISO, CU, CSIRO, GSFC and NOAA) and CCI. c Global mean ocean mass time series (January 2003-December 2012) from GRACE based on the data from CSR, GFZ and JPL (data provided by D. Chambers)
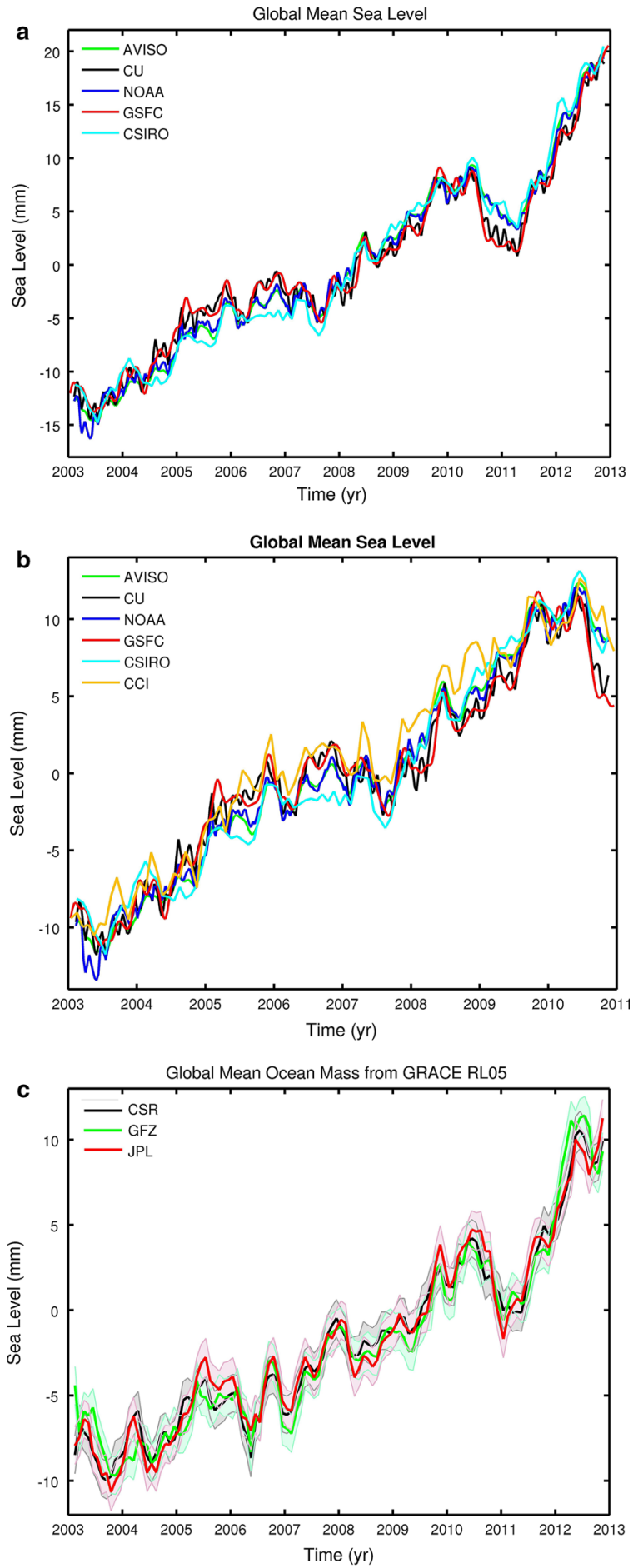
$>$ Table 1 Estimated trends for individual GMSL, ocean mass and steric sea level (for 700 and 1,500 m integration depth) time series, as well as their mean over the P1 and P2 periods

\begin{tabular}{|c|c|c|c|c|c|}
\hline \multirow{2}{*}{$\begin{array}{l}\text { Trend estimates } \\
\text { GMSL (mm/year) }\end{array}$} & \multirow[t]{2}{*}{$\begin{array}{l}\text { January } \\
2003 \text {-December } \\
2010\end{array}$} & \multicolumn{2}{|c|}{$\begin{array}{l}\text { P1: January } \\
\text { 2005-December } \\
2012\end{array}$} & \multicolumn{2}{|c|}{$\begin{array}{l}\text { P2: January } \\
2003 \text {-December } \\
2012\end{array}$} \\
\hline & & & & & \\
\hline AVISO & 2.90 & 2.97 & & 2.97 & \\
\hline $\mathrm{CU}$ & 2.55 & 2.57 & & 2.66 & \\
\hline NOAA & 2.85 & 2.89 & & 2.91 & \\
\hline GSFC & 2.46 & 2.51 & & 2.61 & \\
\hline CSIRO & 2.81 & 3.18 & & 2.99 & \\
\hline MEAN & $2.71 \pm 0.10$ & $2.81 \pm 0.10$ & & $2.82 \pm 0.10$ & \\
\hline $\mathrm{CCI}$ & 2.75 & - & & - & \\
\hline \multicolumn{6}{|l|}{ Ocean mass $(\mathrm{OM})(\mathrm{mm} /$ year$)$} \\
\hline CSR & & $1.85 \pm 0.12$ & & $1.71 \pm 0.08$ & \\
\hline GFZ & & $1.94 \pm 0.12$ & & $1.68 \pm 0.08$ & \\
\hline JPL & & $1.81 \pm 0.12$ & & $1.72 \pm 0.08$ & \\
\hline MEAN & & $1.87 \pm 0.11$ & & $1.70 \pm 0.10$ & \\
\hline \multirow[t]{2}{*}{ Mean GMSL minus mean OM } & & $0.94 \pm 0.16$ & & $1.12 \pm 0.13$ & \\
\hline & & $0-700 \mathrm{~m}$ & $0-1,500 \mathrm{~m}$ & $0-700 \mathrm{~m}$ & $0-1,500 \mathrm{~m}$ \\
\hline \multicolumn{6}{|l|}{ Steric sea level Argo (mm/year) } \\
\hline $\mathrm{KvS}$ & & - & $0.51 \pm 0.15$ & - & - \\
\hline IPRC & & 0.42 & 0.62 & - & - \\
\hline JAMSTEC & & $0.53 \pm 0.13$ & $0.77 \pm 0.16$ & $0.65 \pm 0.14$ & $0.92 \pm 0.17$ \\
\hline SCRIPPS & & 0.41 & 0.63 & - & - \\
\hline MEAN & & - & $0.63 \pm 0.12$ & - & - \\
\hline $\begin{array}{l}\text { Residual (mean GMSL - mean } \\
\text { OM mean - steric sea level) }\end{array}$ & & - & $0.29 \pm 0.21$ & - & - \\
\hline \multicolumn{6}{|l|}{ Steric sea level (mm/year) } \\
\hline IK & & $0.40 \pm 0.13$ & $0.67 \pm 0.14$ & $0.39 \pm 0.11$ & $0.61 \pm 0.16$ \\
\hline EN4 & & - & - & $0.00 \pm 0.14$ & $0.15 \pm 0.17$ \\
\hline NOAA & & - & & 0.29 & - \\
\hline MEAN & & - & - & $0.32 \pm 0.11$ & $0.56 \pm 0.14$ \\
\hline $\begin{array}{l}\text { Residual (mean GMSL - mean } \\
\text { OM mean - steric sea level) }\end{array}$ & & - & - & - & $0.55 \pm 0.19$ \\
\hline ORAS4 Reanalysis (mm/year) & \multicolumn{5}{|c|}{$\begin{array}{l}\text { ORAS4 (Jan. 2003-Dec. 2009): } \\
0-1,500 \mathrm{~m}=0.65 ; 1,500-6,000 \mathrm{~m}=0.07\end{array}$} \\
\hline
\end{tabular}

Uncertainties of mean trends correspond to 1 SD. Residual (mean GMSL - mean ocean mass - mean steric sea level) trends are also provided. ORAS4-based steric trends are also given over 2003-2009

displayed in Fig. 2 shows a positive slope between 2003 and 2007, followed by a temporary negative anomaly of several mm (coinciding with the 2007-2008 La Nina). Since mid-2008, the residual trend is lower than during 2003-2007 but still slightly positive. In addition to systematic errors of each observing system, the residual curve represents in principle the total (full depth) steric component. 


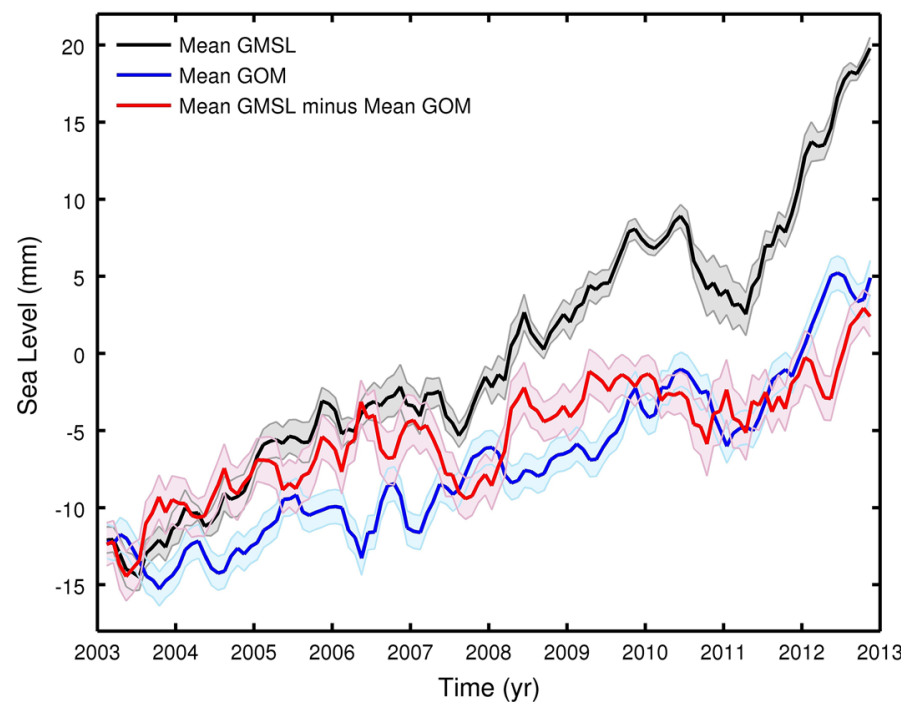

Fig. 2 Averaged GMSL, averaged global mean ocean mass (GOM) and difference time series (January 2003-December 2012)

\subsection{Steric Sea Level Time Series: Comparison Between the 'GMSL Minus GOM' Residual Time Series and Steric Sea Level}

\subsubsection{Period P1 (2005-2012; Argo Time Series)}

Figure 3 shows the four Argo steric time series over 2005-2012 for the 0-1,500 depth range. Uncertainties (available only for the $\mathrm{KvS}$ and Jamstec data sets) are also shown. Important discrepancies of several $\mathrm{mm}$ are noticed at interannual timescales between the four curves. As discussed in detail in Abraham et al. 2013 (see also Lyman and Johnson 2014; von Schuckmann and Le Traon 2011), these differences come from several factors, i.e., quality control, infilling gaps in data coverage, choice of the climatology, gridding process. So far no best processing method can be proposed, and we continue here with a mean Argo time series (as shown in Fig. 4), i.e., the average of the four time series shown in Fig. 3 (called 'mean steric' in the following) and its associated uncertainty (based on the dispersion of individual time series with respect to the mean). We then compare then 'mean steric' curve to the 'GMSL minus GOM' curve (Fig. 4). The mean steric curve displays significant interannual variability that roughly follows that of the 'GMSL minus GOM' curve. Superimposed on the interannual fluctuations, there is positive steric trend amounting to $0.29 \pm 0.21 \mathrm{~mm} /$ year. Figure 4 also shows the residual 'GMSL minus GOM' minus mean steric curve (called 'residual' hereinafter; with a downward offset of $7.5 \mathrm{~mm}$, for clarity). The residual curve reflects errors affecting all data sets (altimetry-based sea level, GRACE-based ocean mass, GIA, Argo data). It also includes the effect of gaps in Argo data coverage (e.g., in the Indonesian region) as well as a potential contribution from the deep ocean below 1,500 $\mathrm{m}$. Interpretation of this residual curve is not straightforward. The early part of the record is characterized by year-to-year oscillations of about 2-4 mm (peak to peak) amplitude, followed by a strong negative anomaly late 2007. Then, from early 2008 to early 2012, the residual curve is rather flat. 


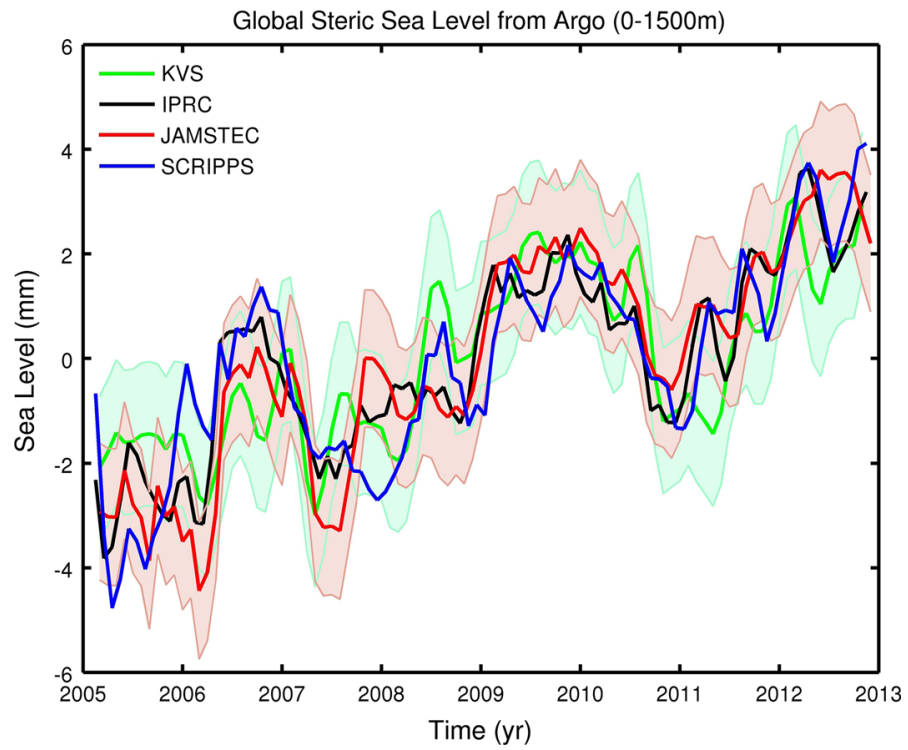

Fig. 3 Argo-based global mean steric sea level from four processing groups (KvS, IPRC, Jamstec and SCRIPPS; January 2005-December 2012)

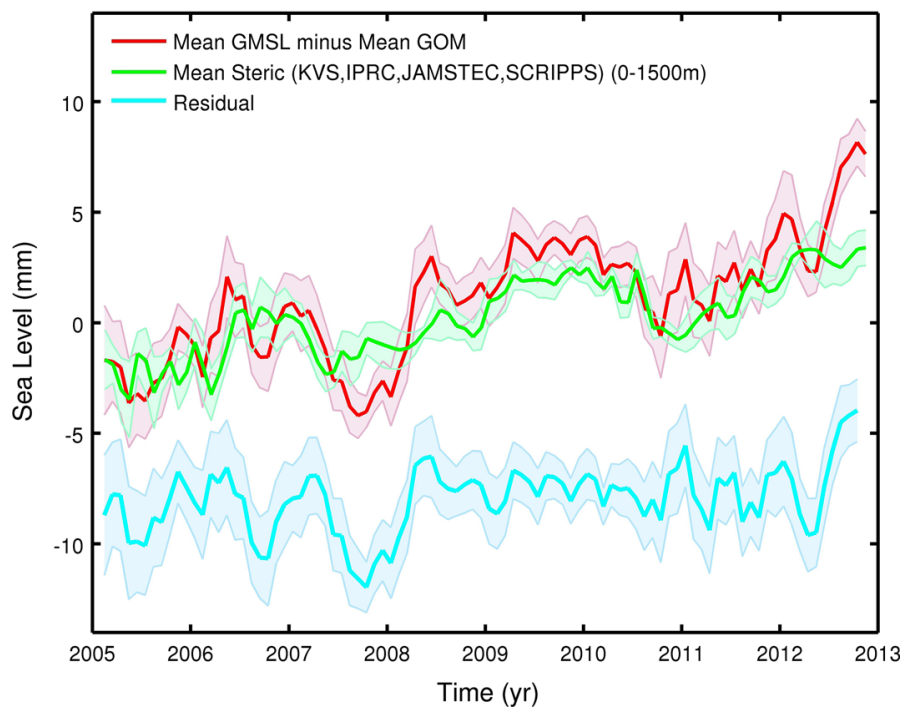

Fig. 4 Difference time series 'GMSL minus GOM' (based on the averaged curves), mean steric sea level (average of KvS, IPRC, Jamstec and SCRIPPS) and residual curve ('GMSL minus GOM' minus mean steric sea level, with downward offset of $7.5 \mathrm{~mm}$ for clarity; January 2005-December 2012)

After mid-2012, the 'GMSL minus GOM' curve increases abruptly, unlike the mean steric curve, causing a steep increase in the residual. Overall, what this residual shows is some step-like rise (around early 2008) preceded and followed by a plateau. Another step-like rise is suggested at the end of the period. 
Table 1 gives the steric trends estimated over the P1 period for each Argo time series (integration down to 1,500 m) and mean steric trend. Trends of 'mean GMSL minus mean GOM' and residual time series over P1 are also given.

\subsubsection{Period P2 (2003-2012; Other Steric Products)}

Over the 2003-2005 time span, only the IK, Jamstec and EN4 data sets provide data over the $0-1,500 \mathrm{~m}$ depth range (however, we must keep in mind the limited raw data available below $700 \mathrm{~m}$ over this time span). So we present below the steric curves for the $0-700$ and $0-1,500 \mathrm{~m}$ depth ranges separately.

Figure 5a shows the IK, Jamstec, NOAA and EN4 steric curves for the 0-700 m depth range, with associated uncertainties for IK, Jamstec and EN4. Very large errors affect the early part of the time span (2003-2005), and strong discrepancies are noticed between the four curves. These differences predominantly occur from data processing methodologies, in particular different gap filling methods. Moreover, prior to 2005-where the data source is mostly based on XBT measurements-differences in the XBT bias correction add to the discrepancies (see Lyman et al. 2010; Abraham et al. 2013; Lyman and Johnson 2014). Figure 5b shows the IK, Jamstec and EN4 steric curves for the 1,500 m depth range. Similar comments apply as for the 0-700 $\mathrm{m}$ depth range. In both cases, the EN4 curve is almost flat over the whole time span (its trend over 2003-2012 is $0.0 \pm 0.14$ and $0.15 \pm 0.17 \mathrm{~mm} /$ year for 700 and $1,500 \mathrm{~m}$ integration depths, respectively). This is unlike the IK and Jamstec curves that display larger positive trends. Over P2, the IK trend amounts $0.39 \pm 0.11$ and $0.61 \pm 0.16 \mathrm{~mm} /$ year down to 700 and $1,500 \mathrm{~m}$, respectively, while the Jamstec trend amounts $0.65 \pm 0.14$ and $0.92 \pm 0.17 \mathrm{~mm} /$ year for the same two integration depth. The behavior of the EN4 time series is puzzling and needs further investigation. However, we still consider this data set in our analysis.

Figure 6 shows the mean of IK, Jamstec, NOAA and EN4 for 0-700 $\mathrm{m}$ and mean of IK, Jamstec and EN4 for 0-1,500 $\mathrm{m}$ depth range (the NOAA data down to 1,500 $\mathrm{m}$ are available only as of 2005) for the 2003-2012 time span (P2 period). Interannual variability is very similar for the 700 and $1,500 \mathrm{~m}$ cases, as expected since it is essentially due to the upper ocean layers. The main difference between the two curves is a $0.24 \mathrm{~mm} /$ year shortterm trend increase, from 700 to $1,500 \mathrm{~m}$.

Steric trends estimated over P2 for each time series (0-700 and 0-1,500 m depth ranges) and means are given in Table 1. Trends of 'mean GMSL minus mean GOM' and residual time series over $\mathrm{P} 2$ are also given.

Figure 7 shows the 'GMSL minus GOM' curve and mean steric curve (average of IK, Jamstec and EN4) for the 0-1,500 m depth, as well as the residual curve ('GMSL minus GOM' minus mean steric curve; with a downward offset of $7.5 \mathrm{~mm}$, for clarity). Over 2005-2012, the residual curve is very similar to that shown in Fig. 4 when using Argo data, with similar behavior though time. Over 2003-2012 (P2 period), the residual curve displays a positive trend of $0.55 \pm 0.19 \mathrm{~mm} /$ year.

\section{Mid-Ocean and Deep Ocean Contribution}

Comparing the upper 700 and 1,500 m steric contributions and their evolution through time shows an interesting behavior. As expected, the $1,500 \mathrm{~m}$ steric contribution is larger than the $700 \mathrm{~m}$ steric one. But, more interestingly, the difference seems to increase linearly with time. This implies that more and more heat reaches the ocean below $700 \mathrm{~m}$. This is 

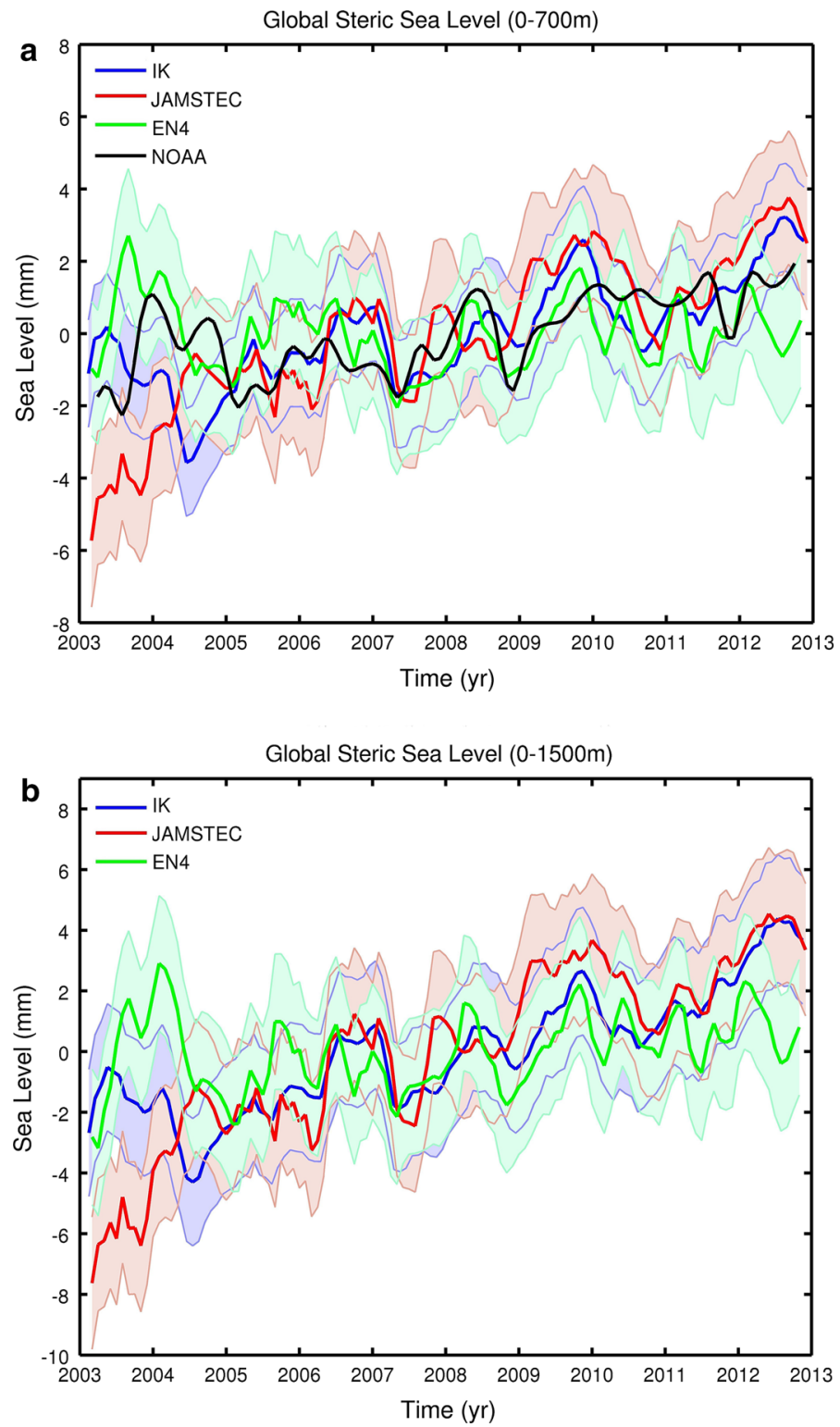

Fig. 5 a Global mean steric sea level time series (January 2003-December 2012; 0-700 m); data from IK, NOAA, Jamstec and EN4. b Global mean steric sea level time series (January 2003-December 2012; 0-1,500 m); data from IK, Jamstec and EN4

observed for all data sets, although not exactly with the same intensity (ranging from 0.15 to $0.27 \mathrm{~mm} /$ year). This is illustrated in Fig. 8, showing the evolution over 2005-2012 of the steric sea level for a few data sets (IPRC, Jamstec, and IK) as well as for their mean (the NOAA and EN4-not shown-show similar behavior). To highlight this timeincreasing difference, the 700 and 1,500 m curves start from the same (arbitrary) value. 


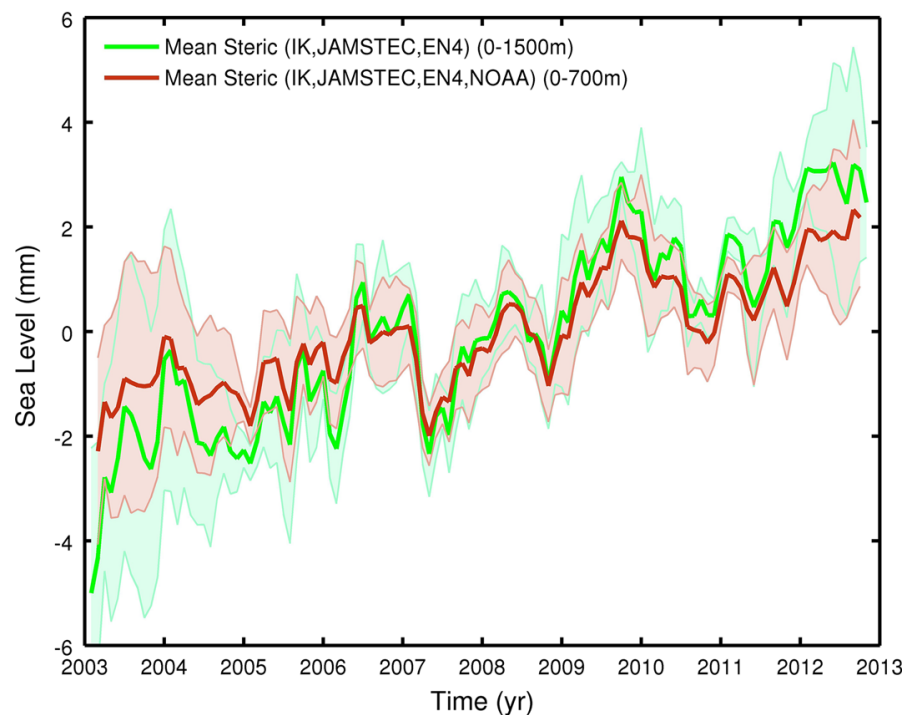

Fig. 6 Averaged steric sea level time series (January 2003-December 2012) for 0-700 m (average of IK, NOAA, Jamstec and EN4) and 0-1,500 m (average of IK, Jamstec and EN4)

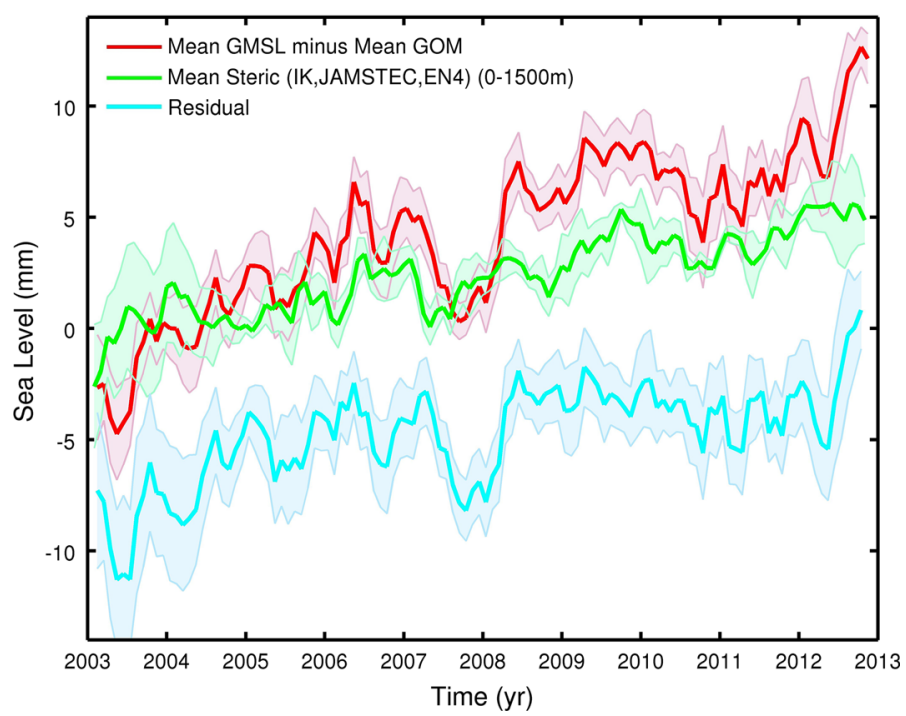

Fig. 7 Difference time series 'GMSL minus GOM' (based on the averaged curves), mean steric sea level for $0-1,500 \mathrm{~m}$ (average of IK, Jamstec and EN4) and residual curve ('GMSL minus GOM' minus mean steric sea level, with downward offset of $7.5 \mathrm{~mm}$ for clarity; January 2003-December 2012)

Figure 8 clearly shows that the layers below $700 \mathrm{~m}$ have gained heat over the last few years. This observation is in agreement with previous results from Levitus et al. (2012) based on the NOAA data set, and Balmaseda et al. (2013a) based on the ORAS4 reanalysis. The latter study showed an increasing warming trend below $700 \mathrm{~m}$. However, it did not 
Fig. 8 Steric sea level curves for $0-700$ and $0-1,500 \mathrm{~m}$ for IK, IPRC, Jamstec and SCRIPPS (January 2005-December 2012)

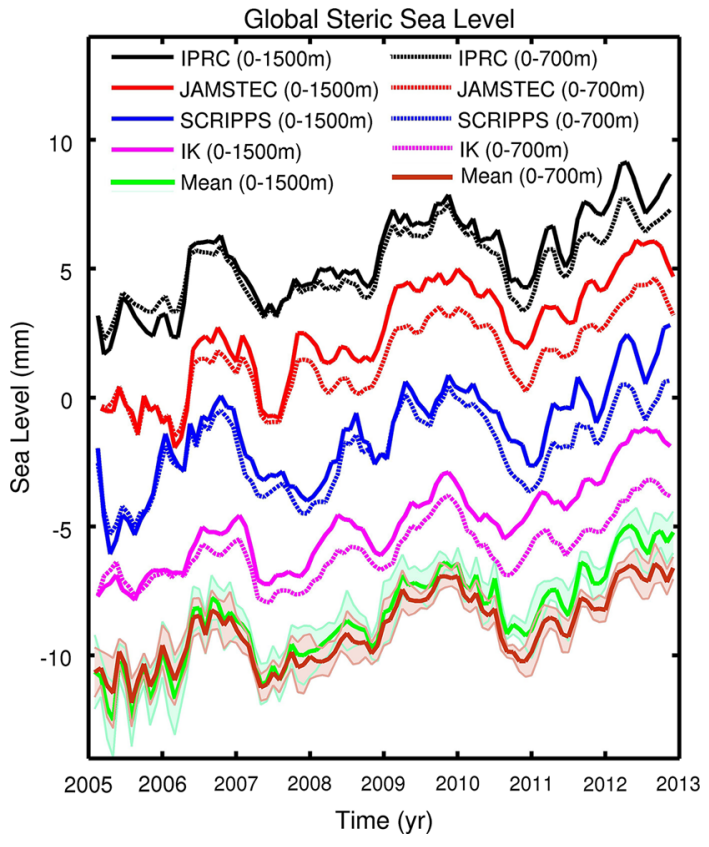

specify in which layers (likely, it is in the 700-1,500 m depth range; see discussion below). A similar behavior was found by Llovel et al. (2014) between 700 and 2,000 m with Argo data.

The residual curves shown in Figs. 4 and 7, i.e., the 'mean GMSL minus mean GOM' minus mean steric down to $1,500 \mathrm{~m}$, reflect errors of all data sets plus missing contributions. For the latter, one candidate is the steric contribution from the deep ocean (below 1,500 m). Direct steric observations below 1,500 $\mathrm{m}$ are very sparse (e.g., Purkey and Johnson 2010; Kouketsu et al. 2011) and not available over the P1 and P2 time spans. However, we can use the ORAS4 reanalysis to compare the deep ocean contribution based on the residual "GMSL minus GOM' minus steric down to 1,500 m" estimated from observations and the ORAS4 reanalysis (Fig. 9). The ORAS4 data set available to us ends in December 2009. So the comparison is performed over 2003-2009 only. Figure 9 superimposes the mean steric and ORAS4 for 0-1,500 $\mathrm{m}$ depth range (upper curves). Very good agreement is found between the two curves. The bottom curves of Fig. 9 correspond to the residual " 'GMSL minus GOM' minus steric down to $1,500 \mathrm{~m}$ " and the ORAS4 steric contribution for the 1,500-6,000 m depth range. Over the 2003-2009 time span, the ORAS4 steric signal below 1,500 is very small, with a trend of $<0.1 \mathrm{~mm} /$ year. This is unlike the residual curve "GMSL minus GOM' minus steric down to 1,500 m" that displays important variability and a large positive trend of $0.55 \pm 0.19 \mathrm{~mm} / \mathrm{year}$ (over 2003-2012). The question whether this trend is significant or not is a difficult one. To the $\sim 0.2 \mathrm{~mm} /$ year formal error, we must add systematic errors associated with each observing system. We can assume systematic errors of $0.4 \mathrm{~mm} /$ year for the GMSL (Ablain et al. 2009, 2014), $0.3 \mathrm{~mm} /$ year for GOM (Chambers and Bonin 2012) and $0.3 \mathrm{~mm} /$ year for the steric sea level. The latter estimate is likely an upper bound, since summing quadratically the total trend errors given for the steric data gives $0.28 \mathrm{~mm} /$ year. Therefore, the resulting (more realistic) error of the residual trend based on the quadratic sum of individual errors is 


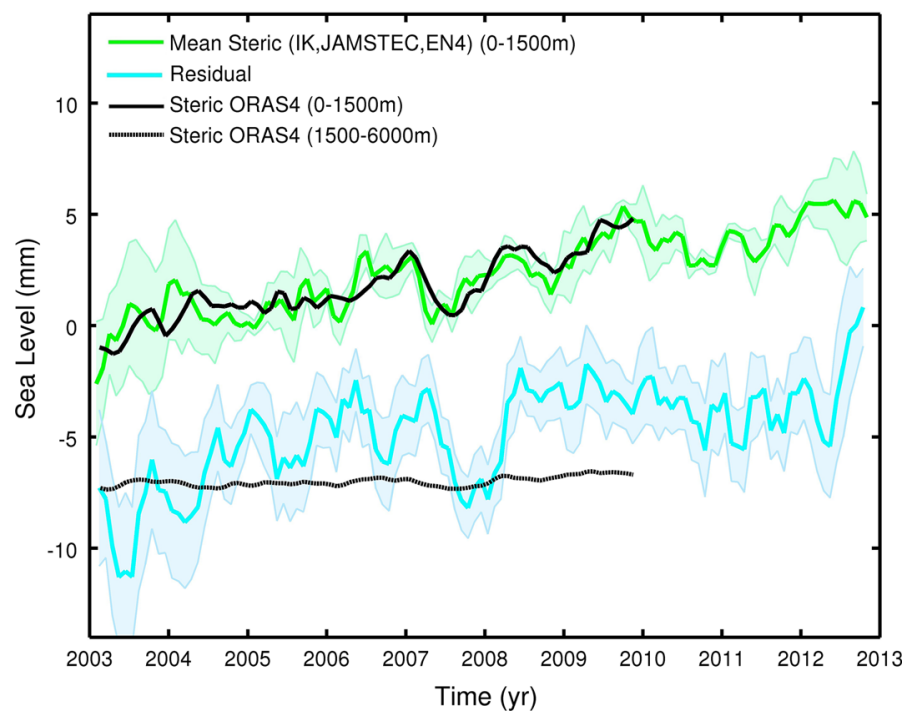

Fig. 9 Upper curves averaged steric sea level for 0-1,500 m (average of IK, Jamstec and EN4; January 2003-December 2012) with steric sea level (0-1,500 m) from ORAS4 superimposed. Lower curves residual curve ('GMSL minus GOM' minus mean steric sea level)—same as in Fig. 7—with the steric sea level $(1,500-6,000 \mathrm{~m})$ from ORAS4 superimposed

$0.58 \mathrm{~mm} /$ year. So the residual trend (of $0.55 \mathrm{~mm} / \mathrm{year}$ ) is barely significant (the large negative anomalies seen in the residual curve prior to mid-2004 are suspect and likely due to data errors).

\section{Discussion and Conclusions}

In this study, we have considered 16 different data sets ( 5 for the GMSL, 3 for the ocean mass and 8 for the steric sea level) to compare the observed GMSL to the sum of components (ocean mass plus steric sea level) and tried to derive constraints on the deep ocean contribution through a sea level closure budget approach. This large number of different data sets would allow 120 different combinations to study the sea level budget. With such an approach, it would always be possible to find some combinations allowing closure of the sea level budget, or inversely leading to nonzero deep ocean contribution. Instead, we used averages of each type of data (GMSL, ocean mass, steric sea level) and estimated their dispersion range. This gives insight into the precision of the different estimates and provides an uncertainty range due to the variants in processing approaches developed by the different groups. On top of this, systematic errors of each observing system have also to be considered.

The main result of our study is that, for the limited time span considered here, the total uncertainty on the "GMSL minus GOM' minus steric $0-1,500 \mathrm{~m}$ " is quite large $(0.58 \mathrm{~mm} /$ year), preventing us from bringing a realistic constraint on the deep (below $1,500 \mathrm{~m}$ ) ocean contribution (as previously noticed in von Schuckmann et al. 2014).

In addition, over both P1 (2005-2012) and P2 (2003-2012) periods, the residual curves (Figs. 4,7 ) display important interannual variability that is totally unrealistic in the deep 
ocean. Very likely, it reflects errors at interannual timescales in one of the components (GMSL, ocean mass or steric sea level) or in all of them. Previous studies (e.g., Cazenave et al. 2012; Masters et al. 2012; Henry et al. 2014; Ablain et al. 2014) showed that at interannual timescales, the (detrended) GMSL time series displays 2-4 $\mathrm{mm}$ differences from one data set to another. Thus, it is quite possible that the year-to-year fluctuations seen here in the residual curves are at least partly due to errors in the GMSL. Current efforts conducted in the context of the ESA Climate Change Initiative 'sea level' project already provide improved sea level data (Ablain et al. 2014), but assessment of this new product is still an ongoing work. Moreover, gaps in coverage in the steric data, in particular Argo data (e.g., in the Indonesian region), and the associated missing steric signal very likely impact the residual time series at interannual timescales.

The short-term trends displayed by the residual curves for both P1 and P2 periods are also very likely contaminated by uncertainties in interannual variability as well as by longer-term systematic errors. As shown in Cazenave et al. (2014), ENSO events cause temporary positive or negative sea level anomalies (mostly of mass origin, but also in the steric component) that significantly alter estimates of the rate of sea level rise. However, even if the short-term variability is removed, the trend estimated from the filtered residual curves (not shown) remain unrealistically large to be attributed to the deep ocean $(>1,500 \mathrm{~m})$ contribution. As shown in Fig. 9, the ORAS4 reanalysis estimates the $1,500-6,000 \mathrm{~m}$ steric trend to $\sim 0.1 \mathrm{~mm} /$ year. Such a magnitude is in line with estimates based on sparse, but direct observations. For example, Purkey and Johnson (2010) report a (non uniform) deep ocean contribution of the order of $0.1 \mathrm{~mm} /$ year for the 1990-2000 decade. For the same time span, Kouketsu et al. (2011) also find observational support for a deep ocean warming, but not larger than $0.1 \mathrm{~mm} /$ year (in steric sea level equivalent) for layers below 3,000 $\mathrm{m}$. Such values agree well with the ORAS4 reanalysis (the ORAS4 steric sea level trend amounts to $0.17 \mathrm{~mm} / \mathrm{year}$ for the 1993-2003 decade and 1,500-6,000 m depth range). Although it can be expected that more heat has reached the deep ocean since the early 2000s, the residual values reported here for the P1 and P2 periods appear anomalously large.

We suspect that gaps in steric data coverage, like in the Indonesian region, and the associated missing signal, contribute to the residual curves over the P1 and P2 periods. For example, in the oceanic region covering the China Sea, Indonesian region and north of Australia, satellite altimetry shows strong positive spatial trends over these two time spans (also observed over the whole altimetry era). As regional sea level trends are mainly of steric origin (e.g., Stammer et al. 2013), it is possible that the residual curves shown in Figs. 4 and 7 reflect at least partly the missing steric signal. To check this, we computed the altimetry-based sea level trend associated with the Indonesian region over the P1 and P2 periods and found that it contributes by $\sim 0.3 \mathrm{~mm} /$ year, hence about $10 \%$ the total sea level trend. Since this region has been considered in the GMSL (as well as in the ocean mass; but a rough estimate indicates a very small mass contribution to the residual trend, less than $0.05 \mathrm{~mm} /$ year), but not is the steric data due to the gap in data coverage (since 2005 but also earlier), we conclude that the steric trend has been underestimated because of these missing data. To investigate this issue somewhat further, we computed the steric contribution of the Indonesian region (considering an area covering the Indonesian region, the Timor Sea plus the South China Sea; see Fig. 10) using the ORAS4 data. The steric contribution of this area to the residual trend is estimated to 0.29 and $0.31 \mathrm{~mm} /$ year over 2003-2009 and 2005-2009, respectively (after weighting by the ratio of the area to the total ocean surface between $66^{\circ} \mathrm{S}$ and $66^{\circ} \mathrm{N}$ ). Assuming that the Indonesian steric trend remains more or less constant over the whole $\mathrm{P} 1$ and $\mathrm{P} 2$ periods and subtracting it (using a 


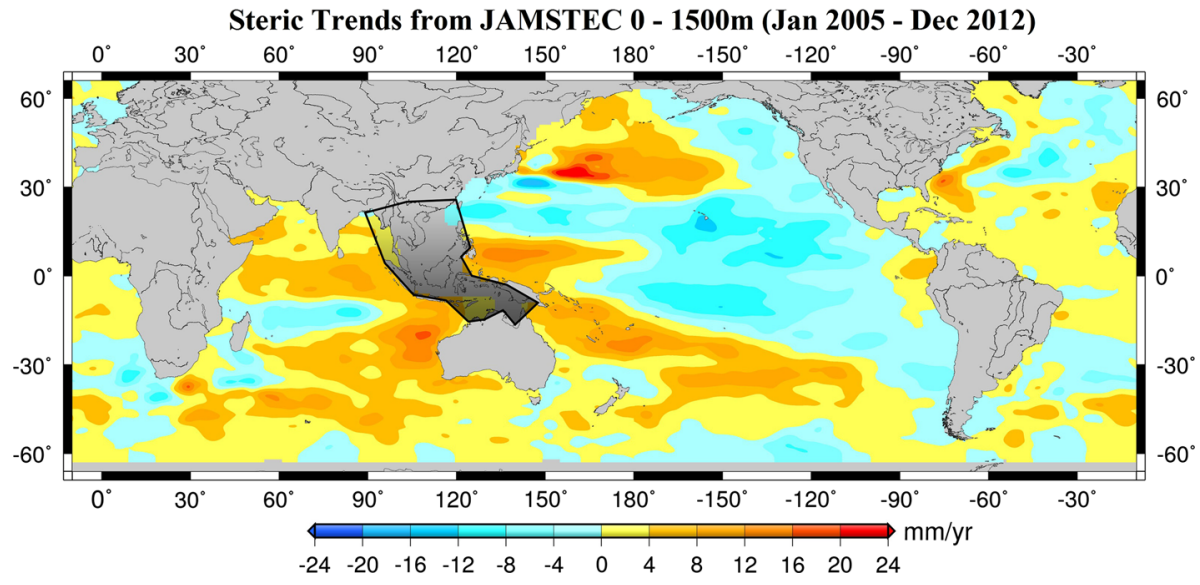

Fig. 10 Steric trend map based on Jamstec data over January 2005-December 2012 showing the Argo data gap in the Indonesian region and the contours (black line) of the area considered in this study to estimateusing the ORAS4 reanalysis-its contribution to the global mean steric trend

value of $0.3 \mathrm{~mm} /$ year) from the above estimated residual trends, we find new residual trends of $\sim 0$ and $0.25 \mathrm{~mm} /$ year for $\mathrm{P} 1$ and $\mathrm{P} 2$, respectively. We consider such a range $(0-0.25 \mathrm{~mm} /$ year $)$ as an upper limit for the deep ocean contribution to recent years sea level rise.

The recently published study by Llovel et al. (2014) uses different data sets (Colorado University/CU altimetry and CSR GRACE data) for the GMSL and ocean mass. They also integrate Argo data down to 2,000 $\mathrm{m}$ (instead of 1,500 $\mathrm{m}$ in our study) and consider the January 2005-December 2013 time span. They come up with a residual trend (GMSL rise corrected for GRACE ocean mass and 0-2,000 m Argo steric trends) of $-0.13 \pm 0.72 \mathrm{~mm} /$ year. That their residual trend is lower than ours (amounting $0.29 \mathrm{~mm} /$ year over 2005-2012; see Table 1) is largely due to the fact that the CU GMSL trend over P1 is lower by $\sim 0.25 \mathrm{~mm} /$ year than the mean GMSL trend used in our study (see Table 1). The remaining difference (on the order of $0.15 \mathrm{~mm} / \mathrm{year}$ ) arises because of differences in the integration depth and study period. Llovel et al. (2014) further consider the upper value of the $\pm 0.72 \mathrm{~mm} /$ year uncertainty range to derive an upper bound for the GMSL rise due to deep ocean warming below 2,000 m. Doing this, they estimate at $0.59 \mathrm{~mm} / \mathrm{year}$ the maximum contribution of the deep ocean warming for the period from 2005 to 2013. This is more than twice our estimate after correcting for the data gap effect. Clearly, more investigations are needed on this important issue.

Probably, the most reliable result of our study is the evidence of a continuing warming of the 700-1,500 m ocean layer. While reported earlier by Levitus et al. (2012) and von Schuckmann et al. (2014) using the NOAA and KvS steric data sets, respectively, Balmaseda et al. (2013a) using the ORAS4 reanalysis, as well as Llovel et al. (2014) using Argo data since 2005, here we observe a similar behavior for each of the eight steric data sets considered over the P1 and P2 periods, indicating that the result is most probably robust. Expressed in steric sea level equivalent, the trend contribution of the 700-1,500 m layer is on the order of $0.2 \mathrm{~mm} /$ year.

As discussed in the introduction, the favored candidate for explaining the current hiatus in global warming is deep ocean heat uptake. In the absence of direct deep ocean 
temperature measurements, the sea level budget approach may in principle help to constrain the problem. But as shown here and in previous studies (e.g., Abraham et al. 2013; von Schuckmann et al. 2014), uncertainties due to data processing approaches and systematic errors of the different observing systems still prevent us from obtaining accurate enough results, even when using almost all available data sets-as done here, instead of just a selection of them. Besides, regional gaps in the steric coverage of the upper ocean, like in the Indonesian region, complicate the sea level budget approach.

Priority for future work is to improve the data processing of each observing system. Systematic intercomparisons of observational products (i.e., sea level, ocean mass and steric sea level-including ocean reanalyses) should be implemented in an international context in order to better understand the causes of the reported differences and define a best processing methodology (if possible). The following step should be a global reprocessing of all data sets, following the approach of the ESA Climate Change Initiative program. In parallel, implementation of new observing systems (e.g., deep Argo) should be a sustained goal of the scientific community and institutional organizations.

Priority in terms of observing systems is definitely the development of a deep Argo program and improved coverage of the upper ocean temperature and salinity measurements, as advocated in a number of recent articles (e.g., Abraham et al. 2013).

Acknowledgments We thank Don Chambers and two anonymous referees for their constructive reviews. We also thank William Llovel for interesting discussions about our respective studies. H.B.D. PhD is funded by the European Space Agency in the context of the Climate Change Initiative Sea Level Project. H.P. is supported by a joint CNES-CLS PhD grant.

Open Access This article is distributed under the terms of the Creative Commons Attribution License which permits any use, distribution, and reproduction in any medium, provided the original author(s) and the source are credited.

\section{References}

Ablain M, Cazenave A, Valladeau G, Guinehut S (2009) A new assessment of the error budget of global mean sea level rate estimated by satellite altimetry over 1993-2008. Ocean Sci 5(2):193-201

Ablain M et al (2014) Improved Sea Level record over the satellite altimetry era 1 (1993-2010) from the Climate Change Initiative project. Ocean Sci (in press)

Abraham JP et al (2013) A review of global ocean temperature observations: implications for ocean heat content estimates and climate change. Rev Geophys 51:450 2013 RG000432

Balmaseda MA, Trenberth K, Kallen E (2013a) Distinctive climate signals in reanalysis of global ocean heat content. Geophys Res Lett 40:1-6. doi:10.1002/grl.50382

Balmaseda MA, Mogensen K, Weaver A (2013b) Evaluation of the ECMWF ocean reanalysis ORAS4. Q J R Meteorol Soc. doi:10.1002/qj.2063

Bindoff N, Willebrand J, Artale V, Cazenave A, Gregory J, Gulev S, Hanawa K, Le Quéré C, Levitus S, Nojiri Y, Shum CK, Talley L, Unnikrishnan A (2007) Observations: oceanic climate and sea level. In: Solomon S, Qin D, Manning M, Chen Z, Marquis M, Averyt KB, Tignor M, Miller HL (eds) Climate change 2007: the physical science basis. Contribution of Working Group I to the fourth assessment report of the intergovernmental panel on climate change. Cambridge University Press, Cambridge and New York

Boening C, Willis JK, Landerer FW, Nerem RS (2012) The 2011 La Nina: so strong, the oceans fell. Geophys Res Lett 39:L19602. doi:10.1029/2012GL053055

Cazenave A, Henry O, Munier S, Meyssignac B, Delcroix T, Llovel W, Palanisamy H, Becker M (2012) ENSO influence on the global mean sea level over 1993-2010. Mar Geod 35(S1):82-97

Cazenave A, Dieng H, Meyssignac B, von Schuckmann K, Decharme B, Berthier E (2014) The rate of sea level rise. Nat Clim Change. doi:10.1038/NCLIMATE2159 
Chambers DP, Bonin JA (2012) Evaluation of Release-05 GRACE time variable gravity coefficients over the ocean. Ocean Sci 8:859-868. doi:10.5194/os-8-859-2012

Chambers DP, Schroeter J (2011) Measuring ocean mass variations from satellite gravimetry. J Geodyn 52:333-343

Chambers DP, Wahr J, Tamisiea ME, Nerem RS (2010) Ocean mass from GRACE and glacial isostatic adjustment. J Geophys Res 115:B11415. doi:10.1029/2010JB007530

Chen X, Tung K-K (2014) Varying planetary heat sink led to global warming slowdown and acceleration. Science 345:897-903

Chen JL, Wilson CR, Tapley BD (2013) Contribution of ice sheet and mountain glacier melt to recent sea level rise. Nat Geosci 6:549-552

Church JA, Clark PU, Cazenave A, Gregory JM, Jevrejeva S, Levermann A, Merrifield MA, Milne GA, Nerem RS, Nunn PD, Payne AJ, Pfeffer WT, Stammer D, Unnikrishnan AS (2013) Sea Level Change. In: Stocker TF, Qin D, Plattner G-K, Tignor M, Allen SK, Boschung J, Nauels A, Xia Y, Bex V, Midgley PM (eds) Climate change 2013: the physical science basis. Contribution of Working Group I to the fifth assessment report of the intergovernmental panel on climate change. Cambridge University Press, Cambridge and New York

England MH et al (2014) Recent intensification of wind-driven circulation in the pacific and the ongoing warming hiatus. Nat Clim Change 4:222-227

Fasullo JT, Boening C, Landerer FW, Nerem RS (2013) Australia's unique influence on global mean sea level in 2010-2011. Geophys Res Lett 40(16):4368-4373. doi:10.1002/grl.50834

Goddard L (2014) Heat hide and seek. Nat Clim Change 4:158161

Good SA, Martin MJ, Rayner NA (2013) EN4: quality controlled ocean temperature and salinity profiles and monthly objective analyses with uncertainty estimates. J Geophys Res Oceans 118:6704-6716. doi:10. 1002/2013JC009067

Guemas V, Doblas-Reyes FJ, Andreu-Burillo I, Asif M (2013) Retrospective prediction of global warming slowdown in the past decade. Nat Clim Change 3:649-653

Hansen J, Sato M, Kharecha P, von Schuckmann K (2011) Earth's energy imbalance and implications. Atmos Chem Phys 11:13421-13449. doi:10.5194/acp-11-13421-2011

Held IM (2013) The cause of the pause. Nature 501:318-319

Henry O, Ablain M, Meyssignac B, Cazenave A, Masters D, Nerem S, Leuliette E, Garric G (2014) Investigating and reducing differences between the satellite altimetry-based global mean sea level time series provided by different processing groups. J Geod 88:351-361. doi:10.1007/s00190-013-0687-3

Ishii M, Kimoto M (2009) Reevaluation of historical ocean heat content variations with time-varying XBT and MBT depth bias corrections. J Oceanogr 65(3):287-299. doi:10.1007/s10872-009-0027-7

Johnson GC, Chambers DP (2013) Ocean bottom pressure seasonal cycles and decadal trends from GRACE Release-05: ocean circulation implications. J Geophys Res Oceans 118:4228-4240. doi:10.1002/jgrc. 20307

Kosaka Y, Xie S-P (2013) Recent global warming hiatus tied to equatorial Pacific surface cooling. Nature 501:403-407

Kouketsu S et al (2011) Deep ocean heat content changes estimated from observation and reanalysis product and their influence on sea level change. J Geophys Res 116:C03012

Leuliette EW, Willis JK (2011) Balancing the sea level budget. Oceanography 24:122-129

Levitus S et al (2009) Global ocean heat content 1955-2008 in light of recently revealed instrumentation problems. Geophys Res Lett 36:L07608. doi:10.1029/2008GL037155

Levitus S, Antonov JI, Boyer TP, Baranova OK, Garcia HE, Locarnini RA, Mishonov AV, Reagan JR, Seidov D, Yarosh ES, Zweng MM (2012) World ocean heat content and thermosteric sea level change (0-2000 m), 1955-2010. Geophys Res Lett 39:L10603. doi:10.1019/2012GL051106

Llovel W, Willis JK, Landerer FW, Fukumori I (2014) Deep-ocean contribution to sea level and energy budget not detectable over the past decade. Nat Clim Change. doi:10.1038/NCLIMATE2387

Lyman JM, Johnson GC (2014) Estimating global ocean heat content changes in the upper $1800 \mathrm{~m}$ since 1950 and the influence of climatology choice. J Clim. doi:10.1175/JCLIM-D-12-00752.1

Lyman JM, Godd SA, Gouretski VV, Ishii M, Johnson GC, Palmer MD, Smith DM, Willis JK (2010) Robust warming of the global upper ocean. Nature 465:334-337. doi:10.1038/nature09043

Masters D, Nerem RS, Choe C, Leuliette E, Beckley B, White N, Ablain M (2012) Comparison of global mean sea level time series from TOPEX/Poseidon, Jason-1, and Jason-2. Mar Geod 35:20-41

Peltier WR (2004) Global glacial isostasy and the surface of the ice-age Earth: the ICE-5G (VM2) model and GRACE. Annu Rev Earth Planet Sci 32:111-149

Peters GP, Marland G, Le Queré C, Boden T, Canadell JG, Raupach MR (2012) Rapid growth in CO2 emissions after the 2008-2009 global financial crisis. Nat Clim Change 2:2-4 
Purkey S, Johnson GC (2010) Warming of global abyssal and deep southern ocean waters between the 1990s and 2000s: contributions to global heat and sea level rise budget. J Clim 23:6336-6351

Shepherd A et al (2012) A reconciled estimate of ice sheet mass balance. Science 338(6111):1183-1189. doi: $10.1126 /$ science. 1228102

Smith D (2013) Has global warming stalled? Nat Clim Change 3:618-6919

Solomon S, Rosenlof K, Portmann R, Daniel J, Davis S, Sanford T, Plattner G-K (2010) Contributions of stratospheric water vapour to decadal changes in the rate of global warming. Science. doi:10.1126/ science. 1182488

Stammer D, Cazenave A, Ponte RM, Tamisiea ME (2013) Causes for contemporary regional sea level changes. Annu Rev Mar Sci 5:21-46. doi:10.1146/annurev-marine-121211-172406

Trenberth KE, Fasullo JT (2010) Tracking Earth's energy. Science 328:316-317

Trenberth KE, Fasullo JT (2013) An apparent hiatus in global warming? Earth's Future. doi:10.102/ 2013EF000165

Trenberth KE, Fasullo JT, Balmaseda MA (2014) Earth's energy imbalance. J Clim 27:3129-3144. doi:10. 1175/JCLI-D-13-00294.1

Von Schuckmann K, Le Traon PY (2011) How well can we derive Global Ocean Indicators from Argo data? Ocean Sci 7(6):783-791. doi:10.5194/os-7-783-2011

Von Schuckmann K, Sallée JB, Chambers D, Le Traon PY, Cabanes C, Gaillard C, Speich S, Hamon M (2014) Consistency of the current global ocean observing systems from an Argo perspective. Ocean Sci 10:547-557. doi:10.5194/os-10-547-2014

Wahr J, Swenson S, Velicogna I (2006) Accuracy of GRACE mass estimates. Geophys Res Lett 33:L06401. doi:10.1029/2005GL025305

Watanabe M, Kamae Y, Yoshimori M, Oka A, Sato M, Ishii M, Mochizuki T, Kimoto M (2013) Strengthening of ocean heat uptake efficiency associated with the recent climate hiatus. Geophys Res Lett 40:3175-3179. doi:10.1002/grl.50541

Woppelmann G, Letetrel C, Santamaria A, Bouin MN, Collilieux X, Altamimi Z, Williams SDP, Miguez BM (2009) Rates of sea-level change over the past century in a geocentric reference frame. Geophys Res Lett. doi:10.1029/2009g1038720 